\title{
Angio-Oedema Induced by Oestrogen Contraceptives Is Mediated by Bradykinin and Is Frequently Associated with Urticaria
}

\author{
C. Giard ${ }^{a}, \quad$ B. Nicolie ${ }^{b, f}$ M. Drouet ${ }^{b, f} \quad$ C. Lefebvre-Lacoeuille ${ }^{c, f}$ J. Le Sellin ${ }^{b}$ \\ J.-C. Bonneau ${ }^{b}$ H. Maillard ${ }^{e} f \quad$ G. Rénier ${ }^{d} \quad$ S. Cichon ${ }^{i-k}$ D. Ponard ${ }^{f, g}$ \\ C. Drouet ${ }^{f, h}$ L. Martin ${ }^{a, f}$
}

Departments of a Dermatology, ${ }^{b}$ Allergology and ${ }^{\mathrm{c}}$ Gynaecology, and ${ }^{\mathrm{d}}$ Laboratory of Immunology, L'UNAM University, Angers Hospital, Angers, ${ }^{e}$ Department of Dermatology, Le Mans Hospital, Le Mans, ${ }^{f}$ CREAK (French Reference Centre of Kinin-Mediated Angio-Oedemas), 9 Laboratory of Immunology, Grenoble University Hospital, and ${ }^{\mathrm{h}}$ AGIM CNRS FRE 3405, Joseph Fourier University, Grenoble, France; 'Institute of Human Genetics, and jDepartment of Genomics, Life \& Brain Center, University of Bonn, Bonn, and kInstitute of Neuroscience and Medicine (INM-1), Research Center Juelich, Juelich, Germany

\section{Key Words}

Angio-oedema - Urticaria - Oestrogen · Bradykinin · High molecular weight kininogen $\cdot \mathrm{C} 1$-inhibitor

\begin{abstract}
Background: Hereditary C1-inhibitor (C1-Inh) deficiency is associated with 'bradykinin-mediated angio-oedema' (BK$\mathrm{AO})$ and is believed not to be associated with urticaria. Acquired $\mathrm{AO}$ has been related to oestrogen contraceptives. Objective: To demonstrate that AO precipitated by oestrogens and characterized by nonfunctional C1-Inh is mediated by $B K$ and to evaluate the occurrence of urticaria in these patients. Methods: A retrospective evaluation of patients referred for $\mathrm{AO}$ related to oestrogen was undertaken. Circulating C1-Inh, high molecular weight kininogen (HK) and enzymes involved in the metabolism of bradykinin were investigated. Results: Fifteen patients were included. HK cleavage concurrent to oestrogen intake was demonstrated in 10 patients with available plasma. Eight patients reported recurrent or chronic urticaria. Discontinuation of the contraceptive resulted in a return to native $\mathrm{C1}$-Inh and HK in all cases
\end{abstract}

studied and to normal kininogenase activity in all but one. The clinical manifestations completely disappeared in 6 patients and improved in 7 after the withdrawal of oestrogen. Conclusion: Patients display extensive cleavage of HK in the plasma, which supports that AO precipitated by oestrogen contraception is BK-mediated. Recurrent urticaria may have been underestimated in this context. The presence of recurrent urticaria should not systematically rule out the diagnosis of BK-AO when the history is suggestive.

Copyright $\odot 2012$ S. Karger AG, Basel

\section{Introduction}

Angio-oedema (AO) refers to sudden and localized swelling in the subcutaneous and/or submucosal tissues [1]. AO is usually white or pale pink and soft. It resolves without sequelae within a few hours or days. Some cases have an unrecognized cause and pathophysiology but most are classified as either histamine-mediated $\mathrm{AO}$ or bradykinin-mediated $\mathrm{AO}$ (BK-AO) [2]; the former often occurs rapidly, is typically associated with urticaria and

\section{KARGER \\ Fax +4161306 1234 \\ E-Mail karger@karger.ch}

www.karger.com
(C) 2012 S. Karger AG, Basel

$1018-8665 / 12 / 2251-0062 \$ 38.00 / 0$

Accessible online at:

www.karger.com/drm
Prof. Ludovic Martin, $\mathrm{MD}, \mathrm{PhD}$

Service de Dermatologie, CHU d'Angers

4 rue Larrey

FR-49933 Angers Cedex 9 (France)

Tel. +33 241353 419, E-Mail LuMartin@ chu-angers.fr 
less frequently with other symptoms of anaphylaxis, such as bronchospasm or shock. The most frequent known cause is hypersensitivity to a drug, insect venom, food or latex. BK-AO is characterized by episodes of recurrent $\mathrm{AO}$ of the extremities, genitalia, abdominal wall, tongue and/or larynx [3]. The digestive tract is also frequently affected, and this suggestive involvement may cause severe abdominal pain as well as transient ascites. BK-AO typically develops gradually, ranging from $24 \mathrm{~h}$ to 9 days. The demonstration of the mediation by BK has been convincingly performed only in exemplary situations, due to the difficulties of measuring $\mathrm{BK}$ [3]. Classically, $\mathrm{BK}-\mathrm{AO}$ is not associated with urticaria. It does not respond (or poorly) to the usual treatment for histamine-mediated $\mathrm{AO}$, i.e. antihistamines and steroids - and if it does, the response is significantly delayed [3].

The best known types of $\mathrm{BK}-\mathrm{AO}$ are associated with a severe functional deficiency of C1-inhibitor (C1-Inh), the serpin that controls the proteases of the classic complement pathway convertase and of the contact system that generates BK from high molecular weight kininogen (HK) [4]. In such patients, C1-Inh activity is usually less than $30 \%$ of standard values. The hereditary deficiency is caused by a monoallelic mutation in the SERPING1 gene which is responsible for the impaired synthesis and/or secretion of C1-Inh (resulting in low plasma antigen levels) in type I, or for a dysfunctional reactive loop in C1Inh (but normal secretion) in type II $[5,6]$. BK-AO can also be acquired, either by the production of antibodies binding to $\mathrm{C} 1$-Inh or $\mathrm{Clq}$ in the context of $\mathrm{B}$ lymphoproliferative disease with gammopathy and/or autoimmune disease, or by uncontrolled proteolysis able to destroy C1Inh (directly or indirectly) in a tumoral setting [7-9].

Iatrogenic BK-AO is increasingly encountered. It is mainly related to angiotensin-I-converting enzyme antagonists, neutral endopeptidase inhibitors, angiotensinII receptor antagonists (sartans) or dipeptidylpeptidase IV inhibitors (gliptins). More recently, cases of AO have been reported associated with mild functional C1-Inh deficiency when using oestrogen contraceptives. Bouillet et al. [10] described 5 female patients who developed recurrent AO after starting oestroprogestative contraceptives. This AO was associated with a slightly lowered C1Inh function (activity greater than $50 \%$ of normal value) and normal serum $\mathrm{C} 4$ antigen levels. Functional deficiency was associated with C1-Inh cleavage on immunoblotting and the presence of a $95-\mathrm{kD}$ molecular species. In most cases, AO resolved completely when contraception was withdrawn. C1-Inh functional deficiency and electrophoretic abnormality were reversible after the causal contraceptive was discontinued. André et al. [11] also reported a female population receiving oral contraceptives suffering from $\mathrm{AO}$ and/or urticaria with a moderate deficiency of C1-Inh function. Discontinuation of oral contraception led to the resolution or improvement of the symptoms in 20 of the 22 patients.

Finally, there is a type of inherited BK-AO with normal SERPING1 gene. It is referred to as AO type III. Only women were affected in the first 10 families described by Bork et al. [12] and the occurrence of $\mathrm{AO}$ was strikingly correlated with oral contraception or pregnancy. Of these 36 women, 14 were evaluated further and were found to have normal C1-Inh antigen levels and function. In all individuals, AO was clinically indistinguishable from hereditary AO types I or II. Binkley and Davis [13] later reported another family with the same phenotype and ruled out any association with the SERPING1 gene or with the promoter of F12, the gene encoding factor XII. We demonstrated autosomal dominant transmission of this type of hereditary $\mathrm{AO}$ in a large family in which men were obligate carriers [14], and finally reported the occurrence of the c.983C $\rightarrow \mathrm{A}$ (p.Thr309Lys) missense mutation in the F12 gene in this French family and in 3 German families. p.Thr309Lys is a gain-of-function mutation that markedly increases FXII activity without altering its plasma levels [15]. Only a small subpopulation of these cases of inherited AO type III was found to have missense mutations in the F12 gene-encoding coagulation factor XII $[15,16]$. Therefore, inherited AO type III is probably genetically, and possibly pathophysiologically, heterogeneous.

Classically, BK-AO and urticaria do not coexist and diagnosis of BK-AO should be excluded if urticaria is present. However, this has not been our experience over the past years with patients referred to CREAK (the French National Reference Centre of Kinin-Mediated Angio-Oedemas) who are suffering from BK-AO with no defects in the SERPING1 gene. In the preliminary study reported here we therefore aimed to demonstrate that $\mathrm{AO}$ developed by female patients following the intake of oestrogenic contraceptives, a biologically well-characterized subpopulation with AO unrelated to SERPING1, was indeed mediated by BK, and we assessed the frequency of urticaria in this condition.

\section{Patients and Methods}

Patients

We retrospectively reviewed the records of women referred to our centre between January 2007 and March 2010 with a clinical history suggestive of $\mathrm{AO}$ attributed to oestrogen contraceptives. 


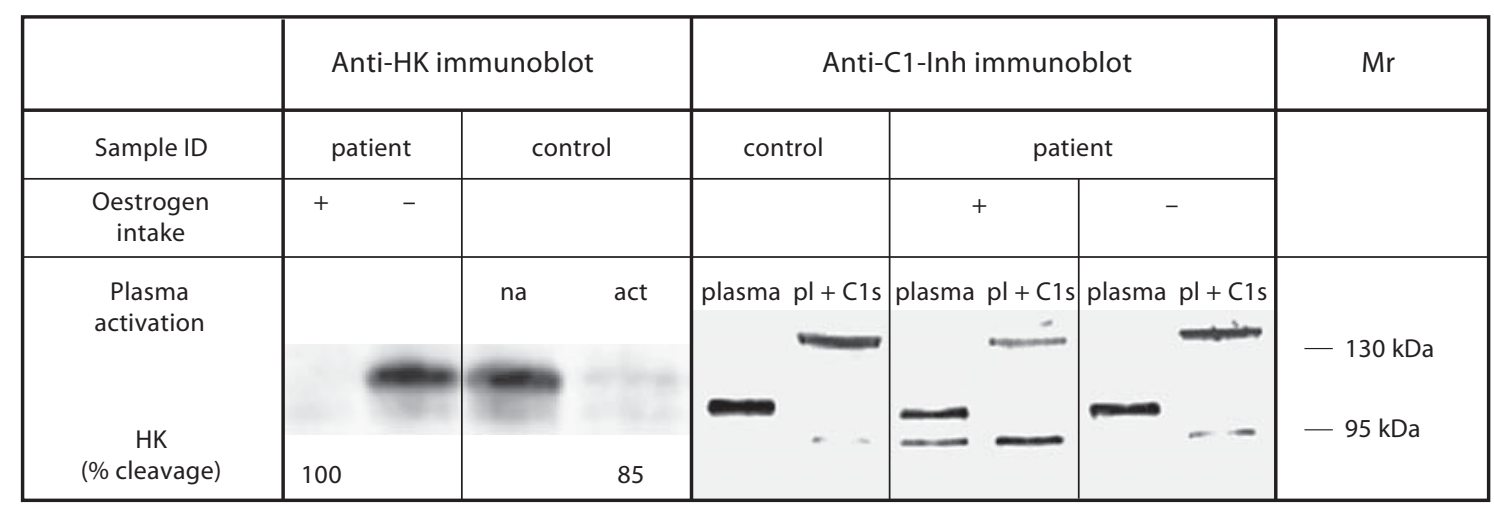

Fig. 1. Plasma samples from patient No. 12. Immunoblotting was performed using HRP-conjugated anti-C1-Inh and anti-HK Lchain antibodies. During oestrogen intake (indicated as + ) the presence of a cleaved, nonfunctional, $95 \mathrm{kDa}$ species of C1-Inh was demonstrated. Controls for anti-HK immunoblot are nonac- tivated (na) and dextran-sulphate activated (act) normal plasma samples. After withdrawal of the contraceptive, C1-Inh and HK present in their native form $(105 \mathrm{kDa}$ for C1-Inh and $110 \mathrm{kDa}$ for $\mathrm{HK}) . \mathrm{Mr}=$ Relative mobility of protein markers.
The inclusion criteria were: (1) A clinical history of AO upon use of oestrogen contraceptive(s), with a poor response to antihistamines, even when given at a high dosage. (2) Evidence of functional deficiency of C1-Inh with residual activity $>50 \%$. (3) Evidence of C1-Inh protein cleavage on immunoblotting (fig. 1). (4) Correction of both biological abnormalities 3 months after discontinuation of the causal contraceptive.

We excluded female patients with inherited BK-AO types I and II worsened by oestrogen exposure. For each patient, a careful standardized telephone interview requested: (1) A clinical history of AO: date of onset, frequency of attacks, trigger factors and locations (including digestive tract involvement). (2) A potential clinical history of urticaria defined by the presence of mobile, transient, and pruriginous erythematous papules and plaques (wheals), including frequency, location, trigger factors, a chronological association with AO (or not) and duration. Acute urticaria was defined as 1-4 isolated episodes, recurrent urticaria (RU) as $>5$ episodes and chronic urticaria (CU) as daily episodes. (3) The name(s) of the contraceptive(s) and date(s) of initiation. (4) The type of contraceptive prescribed at discontinuation of the trigger and the development of $\mathrm{AO}$ and urticaria.

Photographs of skin lesions were requested when available.

Fifty-nine healthy female blood donors on oestrogen contraceptives, aged 18-49 years old, were enrolled to establish the reference intervals for all biological parameters and were questioned about their medical history.

\section{Biological Analyses}

C1-Inh antigen levels and C1-Inh function were assayed as described by Drouet et al. [17]. Briefly, C1-Inh function was measured on the basis of the residual esterase activity of plasma samples after incubation with $\mathrm{C} 1 \mathrm{~s}$ protease. In order to detect any possible serpin breakdown, calculation of C1-Inh specific function (U/mg) was based on the C1-Inh antigen level. Anti-C1-Inh immunoblots (The Binding Site, Saint Egrève, France) were performed in nonreducing conditions on native samples or were submitted to incubation with C1s protease as previously described [16]. Plasma kininogenase (amidase) activity before and after con- traceptive discontinuation was measured using the Pro-Phe-Arg$p$ NA peptide substrate, representative of the 387-389 residue sequence of HK [16]. The anti-HK immunoblot analysis was performed in nonreducing conditions on plasma samples with anti-human HK L-chain horseradish-conjugated sheep antibody (Enzyme Research, Cardiff, UK) and stained by ECL ${ }^{\circledR}$ (Amersham, Courtaboeuf, France). Proteins were electrotransferred on Hybond ${ }^{\circledR}$ with prestained molecular weight markers. Plasma activity of the kininases (aminopeptidase $\mathrm{P}$, carboxypeptidase $\mathrm{N}$ and angiotensin-I-converting enzyme) were assessed according to Adam et al. [18], Cyr et al. [19] and the protocol of the manufacturer (Bühlman, Mulhouse, France), respectively. Informed written consent for mutation analysis was obtained. Genomic DNA was isolated using a guanidine method. The F12 gene was sequenced as previously described [15].

\section{Results}

\section{Patients}

Fifteen female patients were included, corresponding to $17 \%$ of the population suffering from BK-AO followed in our centre. The most frequent causal contraceptives were: Diane ${ }^{\circledR}$ (ethinyloestradiol $35 \mu \mathrm{g}$ and cyproterone acetate $2 \mathrm{mg} ; \mathrm{n}=4$ ) and Trinordiol ${ }^{\circledR}$ and Adepal ${ }^{\circledR}$ (ethinyloestradiol 30-40 $\mu$ g and levonorgestrel 0.15-0.20 mg; $\mathrm{n}=6$ ). Only 1 case was reported for each of the following contraceptives: Melodia ${ }^{\circledR}$ (ethinyloestradiol $15 \mu \mathrm{g}$ and gestodene $0.06 \mathrm{mg}$ ), Moneva ${ }^{\circledR}$ (ethinyloestradiol $30 \mu \mathrm{g}$ and gestodene $0.075 \mathrm{mg}$ ), Efezial ${ }^{\circledR}$ (ethinyloestradiol $20 \mu \mathrm{g}$ and gestodene $0.075 \mathrm{mg}$ ), Jasmine ${ }^{\circledR}$ (ethinyloestradiol $30 \mu \mathrm{g}$ and drospirenone $3 \mathrm{mg}$ ) and the Evra ${ }^{\circledR}$ transdermal contraceptive patch (ethinyloestradiol $600 \mu \mathrm{g}$ and norelgestromin $6 \mathrm{mg}$ ). 
Fig. 2. a AO of the lower part of the face in a patient on oestrogen contraceptives with C1-Inh function deficiency. b Urticarial plaque in the same patient.
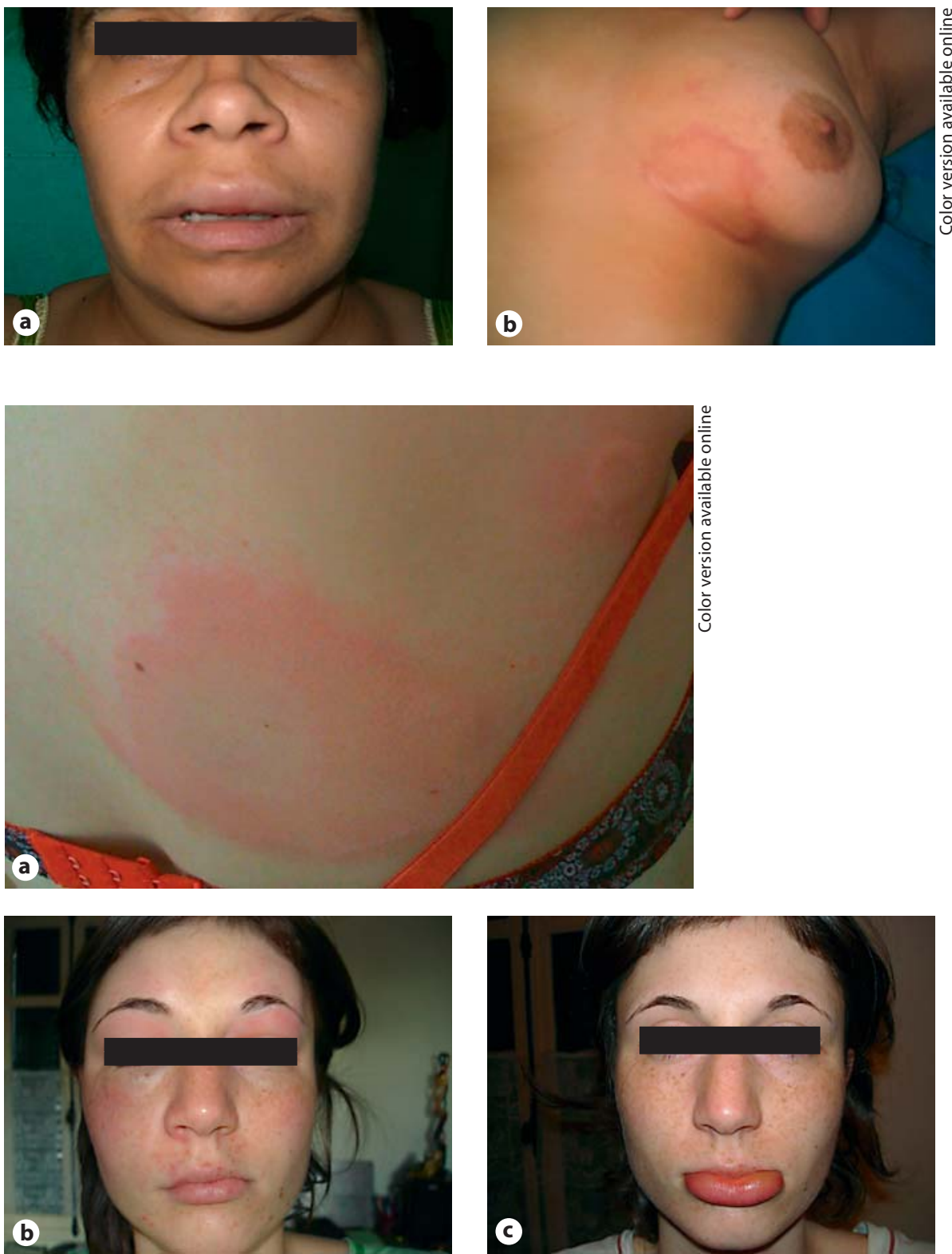

Fig. 3. Asynchronous urticaria on the upper back (a), bilateral, erythematous, palpebral $\mathrm{AO}(\mathbf{b})$ and lower lip $\mathrm{AO}(\mathbf{c})$ in a patient on oestrogen contraceptives with C1Inh function deficiency. toms was 25 years (range 14-37 years). The mean time-lag between introduction of the contraceptive and onset of symptoms was 2.6 years. Symptoms occurred as soon as the first contraceptive was introduced in 9 cases and up to a maximum of 16 years afterwards. Interestingly, they were already present 3 years before contraception began in 1 patient.

Eleven patients (73\%) developed wheals suggestive of urticaria. Three had had acute urticaria, 7 had RU and 1 had CU. For the 7 cases of RU, the frequency of episodes was quarterly $(\mathrm{n}=1)$, monthly $(\mathrm{n}=3)$ and weekly $(\mathrm{n}=3)$. 
For the 8 cases of RU or CU (figs. 2, 3), the episodes of urticaria occurred concomitantly with $\mathrm{AO}$, exclusively in 2 cases, and sometimes independently in the others. Urticaria was always pruriginous, but also painful in 2 patients.

Upon discontinuation of contraception, $\mathrm{AO}$ resolved completely in 6 cases (table 1). The frequency of episodes decreased in 7 other cases and there was no improvement in 2 cases. RU/CU disappeared in 2 patients (but 1 of them still had $\mathrm{AO}$ ), and persisted in the remaining 6 (it remained unchanged in 2) and 5 of them also had recurrent $\mathrm{AO}$.

An association of RU/CU or $\mathrm{AO}$ with contraceptives was not found in the control population.

\section{Biological Analyses}

Proteolytic Cleavage of C1-Inh and $\mathrm{HK}$ during and after Oestrogen Intake. Western blotting of samples with antibodies to C1-Inh and to the L-chain of HK showed the cleavage of both proteins during oestrogen intake, and their return to native forms after withdrawal in 10 cases with available plasma (table 1). This is exemplified in figure 1 with findings from patient No. 12, who completely recovered. During oestrogen intake, the extent of HK cleavage was comparable to that obtained in a dextran-sulphate-activated control sample (fig. 1, 'activated' lane).

Enzymatic Activities. The results are collected in table 1. At the time of diagnosis, 9 patients developed high plasma kininogenase (amidase) activity (in 10 available blood samples). Plasma kininogenase activity was controlled 3-6 months after the discontinuation of contraception in 8 of these 9 patients and returned to normal values in 7. The results from 3 out of 4 patients suffering from both $\mathrm{AO}$ and urticaria, for whom we had plasma samples before and after oestrogen discontinuation, normalized when contraception was discontinued. Amidase activity was normal in 10 out of 11 patients with available plasma after the discontinuation of oestrogen, independently of the disappearance or persistence of symptoms. In the remaining patient, with an only slightly elevated kininogenase level, $\mathrm{AO}$ and urticaria were improved but still present.

Bradykinin Catabolism. The activity of all 3 kininases was within normal limits for the patients for whom it was assessed before and after the discontinuation of contraception.

Genetic Analysis. An F12 gene mutation was absent in the 5 patients who were genotyped (table 1).

\section{Discussion}

This study supports that AO precipitated by oestrogen contraceptives is mediated by $\mathrm{BK}$. It shows that extensive proteolysis of HK (as well as C1-Inh) develops in the context of oestrogen intake and high plasma amidase activity, presumably resulting in the generation of BK, and disappears after the withdrawal of oestrogen and the restoration of native $\mathrm{HK}$ and C1-Inh species. Urticaria was present in 11/15 patients in this series of women suffering from oestrogen-induced BK-AO. Even if 3 cases of acute urticaria would be considered as purely coincidental, RU or $\mathrm{CU}$ was present in 8 women, i.e. $53 \%$ of the population studied. This prevalence of RU/CU is probably higher than in the general population [20,21], especially taking into consideration the short period of evaluation (27 months). The association of RU/CU with oestroprogestative contraceptives was not found in the control population. In addition, to the best of our knowledge, RU/CU is not a known adverse effect of oestrogenic contraceptives reported in pharmacovigilance studies [22-24]. So despite the limitations of our retrospective study, we consider that the association of RU/CU with BK-AO is not just a coincidence in the context of oestrogenic contraception.

The absence of urticaria in the setting of BK-AO is a dogma [25]. It is therefore very difficult to assess whether there might be RU/CU in such patients in the literature as urticaria is generally an exclusion criterion when a series of $\mathrm{BK}-\mathrm{AO}$ patients is constituted [12, 24-26]. However, an association between urticaria and likely BK-AO has already been reported in a population very similar to the population presented here. André et al. [11] reported a series of 26 women with AO and urticaria $(\mathrm{n}=24)$ or urticaria only $(n=2)$ initially attributed to food allergy. All these female patients were in fact taking oral contraception (ethinyloestradiol $35 \mu \mathrm{g}$ and cyproterone acetate $2 \mathrm{mg}$ in 11 cases) and had a slightly decreased C1-Inh function. Discontinuation of contraception in 22 patients led to the normalization of C1-Inh function with resolution of the symptoms in 11 patients, an improvement in 9 and no change in 2 . Other similar but sporadic cases have been reported [27-29].

We believe that the association between RU/CU and BK-AO has probably been underestimated. The chronological association of both manifestations occurring simultaneously during an attack, and their evolution (either recession or persistence of symptoms after the discontinuation of contraception) supports this hypothesis. Such urticarial lesions might be akin to transient reticulate rashes 


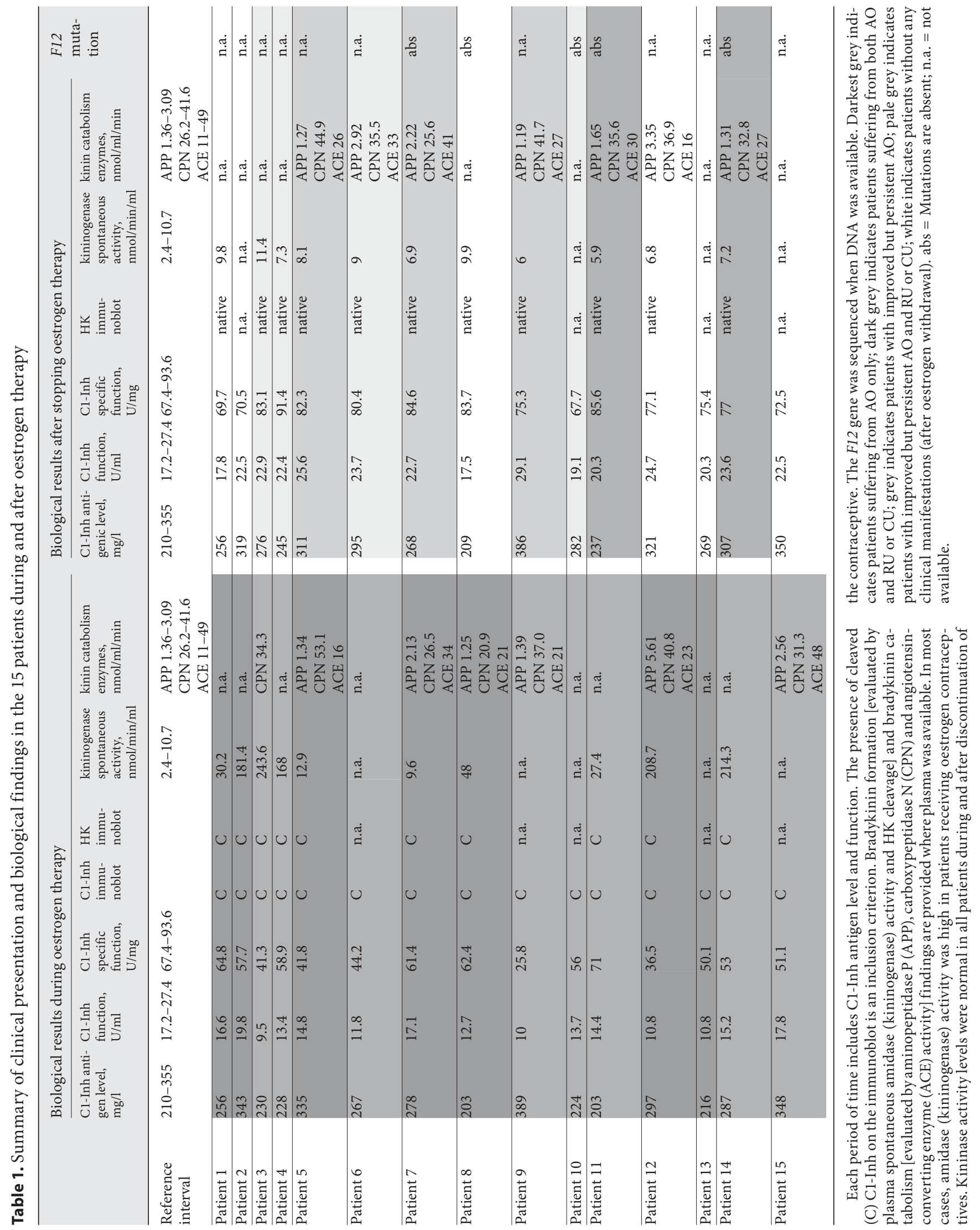


described in hereditary BK-AO types I and II, occurring before bouts of AO [3]. However, the pathophysiology of such phenomena remains to be determined. Mechanistically, it can be envisaged that AO-BK may develop when mast cells are activated, with resulting urticaria, and/or that urticaria may develop because mast cells are challenged when $\mathrm{BK}$ is released. The hypothesis of mast cell activation by anaphylatoxins in the context of BK-AO, resulting in the production of inflammatory mediators from granules, including histamine, might explain the association between BK-AO and RU/CU. High plasma proteolytic activity develops in BK-AO type III and in various situations of BK-AO triggered by oestrogens [16]. The range of protease substrates is not limited to plasma HK. The C1-Inh cleavage observed in our study as well as the development of a convertase with anaphylatoxin production as shown by Di Scipio and Hugli [30] are convincing demonstrations. Finally, though anaphylatoxins are rapidly inactivated by carboxypeptidase $\mathrm{N}$, the long-life $\mathrm{C} 5 \mathrm{a}-$ desArg peptide is of sufficient affinity to mast cell C5a receptor for subsequent activation [31]. In addition, it has been shown that mast cells may precipitate AO-BK via heparin-initiated BK formation [32]. Alternatively, whether BK itself may bind the BK-B2 receptor on the mast cell and trigger degranulation remains to be demonstrated.

This study also provides additional insights into the natural history of oestrogen-induced BK-AO. The physicians should remember that the time interval between the initiation of oestrogen contraception and the occurrence of $\mathrm{BK}-\mathrm{AO}$ is highly variable (from weeks to years), as is the case for other iatrogenic triggers like angiotensin-Iconverting enzyme antagonists. The existence of 1 case of $\mathrm{AO} 3$ years before contraception began and the persistence of $\mathrm{AO}$ in 9 cases out of 15 after the discontinuation of contraception, together with the disappearance of abnormalities of kinogenase activity in most cases, may support the hypothesis of decompensation of a constitutional abnormality of BK production upon introduction of contraception. The well-established oestrogen dependency of hereditary AO types III and I/II strengthens this hypothesis [12, 25], but it is unclear whether some BK-AO precipitated by oestrogens could actually be AO type III independent of F12 mutation. In addition, kininase activity profiles and extension of HK cleavage should be investigated further in order to unmask any correlation with the clinical presentation and evolution.

In conclusion, we showed here that $\mathrm{AO}$ precipitated by oestrogen contraceptives is linked to HK cleavage and is thus presumably BK-mediated. The presence of RU/CU must not rule out the diagnosis of $\mathrm{BK}-\mathrm{AO}$ in this situation when there is a suggestive history. The impact of sustained kinin formation and proteolytic capacity on the indirect histamine release by mast cells in female patients with $\mathrm{BK}-\mathrm{AO}$ should be investigated in order to provide an etiopathogenic explanation for our observations. Whether our findings might be generalized to all BK-AO remains also to be investigated. For clinical practice, to detect a mild and transient decrease in C1-Inh function is an easy way to link sporadic BK-AO occurring in a woman to oestrogen contraception.

\section{Acknowledgements}

This study was supported by a grant from the European Community (EU FP6 E-rare program 2008). The authors are indebted to F. Csopaki, M. Allegret-Cadet, V. Reininger and R. Baroso for skilful technical assistance.

\section{Disclosure Statement}

The authors have no conflicts of interest to declare.

\section{References}

1 Grattan C, Powell S, Humphreys F: Management and diagnostic guidelines for urticaria and angio-oedema. Br J Dermatol 2001;144: 708-714.

2 Kaplan AP, Greaves MW: Angioedema. J Am Acad Dermatol 2005;53:373-388.

3 Frank MM: Hereditary angioedema. J Allergy Clin Immunol 2008;121:S398-S401.

\footnotetext{
4 Wagenaar-Bos IG, Drouet C, Aygoren-Pursun E, Bork K, Bucher C, Bygum A, Farkas H, Fust G, Gregorek H, Hack CE, Hickey A, Joller-Jemelka HI, Kapusta M, Kreuz W, Longhurst H, Lopez-Trascasa M, Madalinski K, Naskalski J, Nieuwenhuys E, Ponard D, Truedsson L, Varga L, Nielsen EW, Wagner E, Zingale L, Cicardi M, van Ham SM: Functional C1-inhibitor diagnostics in hereditary angioedema: assay evaluation and recommendations. J Immunol Methods 2008;338: $14-20$.
}

\footnotetext{
5 Zuraw BL, Herschbach J: Detection of C1 inhibitor mutations in patients with hereditary angioedema. J Allergy Clin Immunol 2000; 105:541-546

-6 Bowen B, Hawk JJ, Sibunka S, Hovick S, Weiler JM: A review of the reported defects in the human $\mathrm{C} 1$ esterase inhibitor gene producing hereditary angioedema including four new mutations. Clin Immunol 2001;98:157-163.
} 
7 Castelli R, Deliliers DL, Zingale LC, Pogliani EM, Cicardi M: Lymphoproliferative disease and acquired $\mathrm{C} 1$ inhibitor deficiency. Haematologica 2007;92:716-718.

8 Zingale LC, Castelli R, Zanichelli A, Cicardi $\mathrm{M}$ : Acquired deficiency of the inhibitor of the first complement component: presentation, diagnosis, course, and conventional management. Immunol Allergy Clin North Am 2006;26:669-690.

-9 Chevailler A, Arlaud G, Ponard D, Pernollet $M$, Carrère F, Renier G, Drouet M, Hurez D, Gardais J: C-1-inhibitor binding monoclonal immunoglobins in three patients with acquired angioneurotic edema. J Allergy Clin Immunol 1996;97:998-1008.

10 Bouillet L, Ponard D, Drouet C, Jullien D, Massot C: Angioedema and oral contraception. Dermatology 2003;206:106-109.

- 11 André F, Veysseyre-Balter C, Rousset H, Descos L, André C: Exogenous oestrogen as an alternative to food allergy in the aetiology of angioneurotic oedema. Toxicology 2003; 185:155-160.

12 Bork K, Barnstedt SE, Koch P, Traupe H: Hereditary angioedema with normal C1-inhibitor activity in women. Lancet 2000;356: 213-217.

-13 Binkley KE, Davis A 3rd: Clinical, biochemical, and genetic characterization of a novel estrogen-dependent inherited form of angioedema. J Allergy Clin Immunol 2000;106: 546-550.

14 Martin L, Degenne D, Toutain A, Ponard D, Watier H: Hereditary angioedema type III: an additional French pedigree with autosomal dominant transmission. J Allergy Clin Immunol 2001;107:747-748.
15 Cichon S, Martin L, Hennies HC, Müller F, Van Driessche K, Karpushova A, Stevens W, Colombo R, Renné T, Drouet C, Bork K, Nöthen MM: Increased activity of coagulation factor XII (Hageman factor) causes hereditary angioedema type III. Am J Hum Genet 2006;79:1098-1104.

16 Martin L, Raison-Peyron N, Nothen MM, Cichon S, Drouet C: Hereditary angioedema with normal $\mathrm{C} 1$ inhibitor gene in a family with affected women and men is associated with the p.Thr328Lys mutation in the F12 gene. J Allergy Clin Immunol 2007;120:975977.

17 Drouet C, Alibeu C, Ponard D, Arlaud G, Colomb M: A sensitive method to assay blood complement C1-inhibitor activity. Clin Chim Acta 1988;174:121-130.

18 Adam A, Cugno M, Molinaro G, Perez M, Lepage Y, Agostoni A: Aminopeptidase P in individuals with a history of angio-oedema on ACE inhibitors. Lancet 2002;359:20882089.

19 Cyr M, Lepage Y, Blais C, Jr., Gervais N, Cugno M, Rouleau JL, Adam A: Bradykinin and des-Arg(9)-bradykinin metabolic pathways and kinetics of activation of human plasma. Am J Physiol Heart Circ Physiol 2001; 281:H275-H283.

20 Zuberbier T, Balke M, Worm M, Edenharter G, Maurer M: Epidemiology of urticaria: a representative cross-sectional population survey. Clin Exp Dermatol 2010;35:869-873.

21 Paul E, Greilich KD: Epidemiology of urticaria diseases. Hautarzt 1991;42:366-375.

22 Amy JJ, Tripathi V: Contraception for women: an evidence based overview. BMJ 2009; 339:b2895.

-23 Erkkola R: Recent advances in hormonal contraception. Curr Opin Obstet Gynecol 2007;19:547-553.
24 Bork K, Fischer B, Dewald G: Recurrent episodes of skin angioedema and severe attacks of abdominal pain induced by oral contraceptives or hormone replacement therapy. Am J Med 2003;114:294-298.

25 Bork K, Gül D, Hardt J, Dewald G: Hereditary angioedema with normal $\mathrm{C} 1$ inhibitor: clinical symptoms and course. Am J Med 2007;120:987-992.

-26 Cicardi M, Bergamaschini L, Zingale LC, Gioffré D, Agostoni A: Idiopathic nonhistaminergic angioedema. Am J Med 1999;106: 650-654.

-27 Jorge AS, Dortas SD, Valle SO, Franca AT: Hereditary angioedema and chronic urticaria: is there a possible association? J Investig Allergol Clin Immunol 2009;19:327-328.

28 Pichler WJ, Lehner R, Späth PJ: Recurrent angioedema associated with hypogonadism or anti-androgen therapy. Ann Allergy 1989; 63:301-305.

29 Warin RP, Cunliffe WJ, Greaves MW, Wallington TB: Recurrent angioedema: familial and oestrogen-induced. Br J Dermatol 1986; 115:731-734

30 Di Scipio RG, Hugli TE: The architecture of complement component C9 and poly(C9). J Biol Chem 1985;260:14802-14809.

-31 Köhl J: The role of complement in danger sensing and transmission. Immunol Res 2006;34:157-176.

32 Oschatz C, Maas C, Lecher B, Jansen T, Björkqvist J, Tradler T, Sedlmeier R, Burfeind P, Cichon S, Hammerschmidt S, Müller-Esterl W, Wuillemin WA, Nilsson G, Renné T: Mast cells increase vascular permeability by heparin-initiated bradykinin formation in vivo. Immunity 2011;34:258-268. 